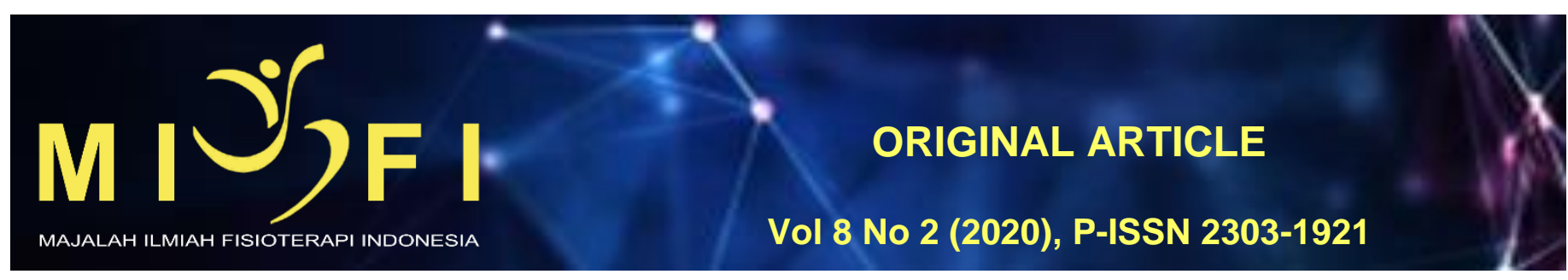

\title{
PREVALENSI HALLUX VALGUS PADA GURU DAN PEGAWAI DI SEKOLAH MENENGAH KEJURUAN PARIWISATA DALUNG DI BADUNG
}

\author{
Ni Kadek Angel Puri Asih ${ }^{1}$, Indira Vidiari Juhanna², I Made Niko Winaya ${ }^{3}$, Sayu Aryantari Putri Thanaya ${ }^{3}$ \\ ${ }^{1}$ Program Studi Sarjana Fisioterapi dan Profesi Fisioterapi, Fakultas Kedokteran Universitas Udayana \\ ${ }^{2}$ Departemen IImu Faal, Fakultas Kedokteran Universitas Udayana \\ ${ }^{3}$ Departemen Fisioterapi, Fakultas Kedokteran Universitas Udayana \\ angelpuriasih.27m@gmail.com
}

\begin{abstract}
ABSTRAK
Hallux Valgus (HV) adalah kelainan bentuk kaki yang sangat umum terjadi pada masyarakat modern. Hallux valgus merupakan kelainan bentuk pada ibu jari kaki dimana terjadi deviasi lateral akibat peningkatan adduksi metatarsal pertama terhadap sendi tarsometatarsal. Tujuan dari penelitian ini adalah untuk mengetahui prevalensi hallux valgus dan memberikan gambaran proporsi HV berdasarkan jenis kelamin, usia, dan indeks massa tubuh (IMT) pada guru dan pegawai di Sekolah Menengah Kejuruan Pariwisata Dalung di Badung. Penelitian ini menggunakan desain deskriptif dengan pendekatan potong lintang dengan jumlah sampel sebanyak 100 orang (51 pria dan 49 wanita) dengan rentang usia 21-66 tahun. Variabel dalam penelitian ini yaitu hallux valgus, jenis kelamin, usia, dan IMT. Hasil penelitian menunjukkan bahwa prevalensi penderita HV pada guru dan pegawai di Sekolah Menengah Kejuruan Pariwisata Dalung di Badung sebanyak 40\%. Proporsi penderita HV berdasarkan jenis kelamin lebih besar pada wanita daripada pria, berdasarkan usia lebih besar pada kelompok usia 26-35 tahun, berdasarkan indeks massa tubuh (IMT) yang terbanyak adalah pada kategori obese.
\end{abstract}

Kata Kunci : prevalensi, hallux valgus, guru, pegawai

\section{PREVALENCE OF HALLUX VALGUS IN TEACHERS AND EMPLOYEES AT DALUNG TOURISM VOCATIONAL HIGH SCHOOL IN BADUNG}

\begin{abstract}
Hallux Valgus (HV) is a foot deformity that is very common in modern society. Hallux valgus is a deformity in the toes where lateral deviations occur due to an increase in the first metatarsal adduction to the tarsometatarsal joint. The aim of this study was to determine the prevalence of hallux valgus and provide an overview of proportions based on gender, age, and body mass index (BMI) in teachers and employees at Dalung Tourism Vocational High School in Badung. This study used a descriptive design with a cross-sectional with a total sample of 100 people (51 males and 49 females) with an age range of 21-66 years. The variables in this study were hallux valgus, gender, age, and BMI. The results showed that the prevalence of HV patients in teachers and employees at Dalung Tourism Vocational High School in Badung was $40 \%$. The proportion of HV patients based on gender is greater in females than males, whereas based on age is greater in the 26-35 year age group, based on the body mass index (BMI) highest in the obesity category.

Keywords: prevalence, hallux valgus, teachers, employees
\end{abstract}

\section{PENDAHULUAN}

Kaki merupakan bagian dari anggota gerak tubuh yang berperan penting dalam menopang tubuh manusia. Terjaganya fungsi dan struktur kaki akan mengurangi masalah kesehatan yang mungkin timbul pada kaki. Pada umumnya, masalah kesehatan kaki yang telah memunculkan gejala akan lebih diperhatikan dibandingkan dengan masalah kesehatan kaki yang belum memunculkan gejala. Hal ini menyebabkan masalah kaki yang memerlukan perjalanan waktu yang lama untuk menimbulkan gejala akan diabaikan.

Masalah utama yang bisa terjadi pada kaki adalah kelainan bentuk kaki. Kelainan bentuk kaki umumnya merupakan hasil patofisiologi dari kondisi yang kronik. ${ }^{1}$ Salah satu kelainan bentuk pada kaki adalah kelainan bentuk ibu jari kaki yang disebut hallux valgus. Hallux Valgus (HV) adalah kelainan bentuk kaki yang sangat umum terjadi pada masyarakat modern. ${ }^{2} \mathrm{HV}$ atau bunion merupakan deviasi lateral dari ibu jari kaki yang progresif dan dikaitkan dengan peningkatan adduksi dari metatarsal pertama terhadap sendi tarsometatarsal.3.4

Kondisi HV lebih dikarenakan oleh kombinasi beberapa faktor daripada oleh satu faktor. ${ }^{5}$ Faktor yang mempengaruhi HV dapat dibagi menjadi faktor ekstrinsik dan faktor intrinsik dimana yang termasuk dalam faktor ekstrinsik adalah alas kaki dan indeks massa tubuh (IMT), sedangkan faktor intrinsik seperti faktor genetik, usia, jenis kelamin, dan ligament laxity. ${ }^{6}$ Memahami faktor-faktor risiko dari HV dapat dilakukan untuk mencegah dan meminimalkan perkembangan HV. ${ }^{7}$

Pada sendi metatarsophalangeal yang mengalami HV sering terjadi peradangan dan nyeri. Orang dengan HV akan menghindari pembebanan pada metatarsophalangeal pertama sehingga menyebabkan pembebanan yang lebih besar pada tulang metatarsal lateral. Kondisi HV yang parah dapat menyebabkan osteoarthritis sendi metatarsophalangeal, metatarsus varus, valgus (deviasi lateral) ibu jari, pembentukan bunion dan bursitis pada bagian 
medial sendi metatarsophalangeal. Intervensi berupa bedah sering disarankan pada kasus yang dikatakan sebagai deformitas dan disfungsi. ${ }^{4}$ Perubahan biomekanik pada kaki mengakibatkan ketidakseimbangan yang menyebabkan perpindahan tumpuan berat badan kearah lateral dan kemudian terjadi peningkatan tekanan sehingga timbul rasa sakit pada kepala metatarsal atau yang disebut dengan metatarsalgia. ${ }^{3}$

HV memiliki dampak merugikan pada kualitas hidup diantaranya adalah gangguan pola berjalan, keseimbangan dan nantinya seiring dengan penambahan usia akan meningkatkan risiko jatuh. ${ }^{8}$ Penanganan HV dapat dilakukan dengan intervensi bedah, namunintervensi bedah memerlukan biaya yang mahal.Maka dariitu, penatalaksanaan konservatif dari HV secara umum ditujukan untuk mengurangi atau menunda intervensi bedah yaitu dengan penggunaan orthosis kaki, sepatu rocker tunggal dan/atau terapi fisik untuk memperbaiki fungsi dan mengurangi rasa sakit. 7,9

Pada sebuah penelitian meta analisis dikatakan bahwa prevalensi HV pada anak usia kurang dari 18 tahun adalah 7,8\%, pada orang dewasa berusia 18-65 tahun 23\%, dan pada orang tua berusia diatas 65 tahun $35,7 \%$. Hal ini menunjukkan bahwa prevalensi HV meningkat seiring dengan pertambahan usia. ${ }^{10}$ Pada penelitian yang dilakukan di Nigeria ditemukan bahwa prevalensi HV pada mahasiswa kedokteran lebih tinggi pada wanita yaitu sebesar $11 \%$ dibanding pria dengan prevalensi sebesar $5 \% .{ }^{5}$ Pada penelitian yang dilakukan di St. Helena oleh Shine ${ }^{11}$ ditemukan bahwa HV pada orang yang tidak menggunakan sepatu sebanyak $2 \%$ dan pada orang yang menggunakan sepatu sebanyak $16 \%$ pada pria serta $48 \%$ pada wanita.

Beberapa pekerjaan menuntut kerapian dari pegawainya, hal ini pula yang terjadi pada pekerjaan sebagai guru dan pegawai. Seorang guru dituntut untuk berpenampilan rapi dengan menggunakan sepatu ketika bekerja dan tidak jarang guru wanita menggunakan sepatu hak tinggi. Tanpa disadari dengan menggunakan sepatu yang kurang tepat, HV mulai muncul dan berkembang.Oleh karena itu, data epidemiologi terkait HV pada populasi guru dan pegawai di Bali terutama di Badung diperlukan untuk mengetahui besar kejadian HV pada populasi guru dan pegawai.

\section{METODE}

Rancangan penelitian yang digunakan dalam penelitian ini yaitu desain deskriptif dengan pendekatan potong lintang. Penelitian ini dilakukan di Sekolah Menengah Kejuruan Pariwisata Dalung di Badung pada tanggal 6 April 2019 sampai 12 April 2019. Sebanyak 100 sampel penelitian digunakan pada penelitian ini yaitu 51 orang pria dan 49 orang wanita. Teknik pengambilan sampel yang digunakan adalah total sampling dan memenuhi kriteria inklusi seperti menggunakan sepatu saat bekerja dan kriteria eksklusi yaitu memiliki cacat fisik akibat trauma atau operasi pada daerah kaki yang akan diukur dan sedang mengalami cedera pada ibu jari kaki.

Setelah mengisi informed consent serta memenuhi kriteria inklusi dan eksklusi, berat badan dan tinggi badan subjek diukur untuk menentukan IMT serta pengukuran sudut ibu jari kaki dengan menggunakan goniometer.

Pengukuran dengan goniometer dilakukan dengan cara pusat rotasi goniometer diletakkan pada sendi MTP pada bagian medial kaki. Satu lengan goniometer diletakkan sejajar dengan bagian medial metatarsal pertama dan lengan lainnya diletakkan pada bagian medial dari phalang proksimal hallux. Pengukuran dengan goniometer dilakukan dengan tiga kali pengukuran dan diambil rata-ratanya. ${ }^{12}$

Analisis data yang digunakan dalam penelitian ini adalah software SPSS dan data yang didapat dari hasil penelitian ini akan menggambarkan distribusi frekuensi dari variabel penelitian yang terdiri dari hallux valgus, jenis kelamin, usia, dan IMT.Klasifikasi sudut HVdapat dibedakan menjadi normal, mild, moderate, dan severe. Dikatakan normal bila sudut $\mathrm{HV}<15^{\circ}$, mild bila sudut $\mathrm{HV}<20^{\circ}$, moderate $20^{\circ}-40^{\circ}$, dan severe $>40^{\circ} .{ }^{13}$

\section{HASIL}

Karakteristik sampel berdasarkan jenis kelamin, usia, dan IMT adalah sebagai berikut.

Tabel 1. Karakteristik Sampel

\begin{tabular}{lcc}
\hline \multicolumn{1}{c}{ Karakteristik } & $\begin{array}{c}\text { Frekuensi } \\
\text { (n) }\end{array}$ & $\begin{array}{c}\text { Presentase } \\
\text { (\%) }\end{array}$ \\
\hline Jenis Kelamin & & \\
\hline Pria & 51 & 51 \\
Wanita & 49 & 49 \\
\hline Usia & & \\
\hline 17-25 tahun & 9 & 9 \\
26-35 tahun & 54 & 54 \\
36-45 tahun & 15 & 15 \\
46-55 tahun & 16 & 16 \\
56-65 tahun & 4 & 4 \\
65 tahun sampai akhir & 2 & 2 \\
\hline IMT & & \\
\hline Underweight $(<18.50)$ & 4 & 4 \\
Normal $(18.50-24.99)$ & 53 & 53 \\
Overweight $(\geq 25.00)$ & 31 & 31 \\
Obese $(\geq 30.00)$ & 12 & 12 \\
\hline
\end{tabular}

Berdasarkan Tabel 1 dapat diketahui distribusi frekuensi sampel berdasarkan jenis kelamin, usia, dan IMT. Karakteristik sampel berdasarkan jenis kelamin diketahui sebanyak 51 orang $(51 \%)$ adalah pria dan 49 orang $(49 \%)$ adalah wanita. Karakteristik sampel berdasarkan usia diketahui sebanyak 9 orang (9\%) berusia 17-25 tahun, 54 orang (54\%) berusia 26-35 tahun, 15 orang (15\%) berusia 36-45 tahun, 16 orang (16\%) berusia 46-55 tahun, 4 orang berusia 
56-65 tahun, dan 2 orang (2\%) berusia diatas 65 tahun. Karakteristik berdasarkan IMT didapatkan sebanyak 4 orang (4\%) underweight, 53 orang (53\%) normal, 31 orang (31\%) overweight, dan obese sebanyak 12 orang (12\%).

Tabel 2. Prevalensi Penderita Hallux Valgus

\begin{tabular}{lcc}
\hline Hallux Valgus & $\begin{array}{c}\text { Frekuensi } \\
(\mathbf{n})\end{array}$ & $\begin{array}{c}\text { Presentase } \\
(\%)\end{array}$ \\
\hline $\mathrm{HV}$ & 40 & 40 \\
Normal & 60 & 60 \\
\hline Total & 100 & 100 \\
\hline
\end{tabular}

Berdasarkan Tabel 2 maka diketahui bahwa prevalensi penderita HV dari 100 sampel didapat sebanyak 40 orang (40\%) HV dan sebanyak 60 orang (60\%) normal atau tidak menderita hallux valgus.

Tabel 3. Tabulasi Silang Distribusi Jenis Kelamin dan Hallux Valgus

\begin{tabular}{lccc}
\hline & $\begin{array}{c}\text { Jumlah Sampel } \\
\text { (n) }\end{array}$ & $\begin{array}{c}\text { Hallux Valgus } \\
\text { (n) }\end{array}$ & $\begin{array}{c}\text { Frekuensi } \\
(\%)\end{array}$ \\
\hline Jenis Kelamin & & & Presentase \\
Pria & 51 & 15 & $29,4 \%$ \\
Wanita & 49 & 25 & $51,0 \%$ \\
\hline
\end{tabular}

Berdasarkan Tabel 3 maka diketahui bahwa proporsi penderita HV pada kelompok jenis kelamin pria sebanyak 29,4\% dimana dalam 51 sampel terdapat 15 orang dengan HV. Proporsi penderita HV pada kelompok jenis kelamin wanita sebanyak $51,0 \%$ dimana terdapat 25 orang dengan HV dalam 49 sampel wanita.

Tabel 4. Tabulasi Silang Distribusi Usia dan Hallux Valgus

\begin{tabular}{|c|c|c|c|}
\hline & \multirow[b]{2}{*}{$\begin{array}{c}\text { Jumlah Sampel } \\
\text { (n) }\end{array}$} & \multicolumn{2}{|c|}{ Hallux Valgus } \\
\hline & & $\begin{array}{l}\text { Frekuensi } \\
\text { (n) }\end{array}$ & $\begin{array}{c}\text { Presentase } \\
(\%)\end{array}$ \\
\hline \multicolumn{4}{|l|}{ Usia } \\
\hline 17-25 tahun & 9 & 3 & $33,3 \%$ \\
\hline 26-35 tahun & 54 & 26 & $48,1 \%$ \\
\hline 36-45 tahun & 15 & 4 & $26,7 \%$ \\
\hline 46-55 tahun & 16 & 6 & $37,5 \%$ \\
\hline 56-65 tahun & 4 & 1 & $25,0 \%$ \\
\hline 65 tahun sampai akhir & 2 & 0 & $0,0 \%$ \\
\hline
\end{tabular}

Berdasarkan Tabel 4 maka diketahui bahwa proporsi penderita HV pada kelompok usia 17-25 tahun sebanyak $33,3 \%$ dimana dalam 9 sampel terdapat 3 orang dengan HV. Proporsi penderita HV pada kelompok usia 26-35 tahun sebanyak 48,1\% dimana terdapat 26 orang dengan HV dalam 54 sampel. Proporsi penderita HV pada kelompok usia 36-45 tahun adalah 26,7\% dimana dari 15 sampel, 4 diantaranya merupakan penderita HV. Proporsi penderita HV pada kelompok usia 46-55 tahun sebanyak 37,5\% dimana dalam 16 sampel terdapat 6 orang dengan HV. Proporsi penderita HV pada kelompok usia 56-65 tahun sebanyak 25,0\% dimana terdapat 1 orang dengan HV dalam 4 sampel. Proporsi penderita HV pada kelompok usia 65 tahun keatas adalah 0,0\% dimana dari 2 sampel, tidak ada yang merupakan penderita HV.

Tabel 5. Tabulasi Silang Distribusi IMT dan Hallux Valgus

\begin{tabular}{|c|c|c|c|}
\hline & \multirow[b]{2}{*}{$\begin{array}{c}\text { Jumlah Sampel } \\
\text { (n) }\end{array}$} & \multicolumn{2}{|c|}{ Hallux Valgus } \\
\hline & & $\begin{array}{c}\text { Frekuensi } \\
\text { (n) }\end{array}$ & $\begin{array}{c}\text { Presentase } \\
(\%)\end{array}$ \\
\hline \multicolumn{4}{|l|}{ IMT } \\
\hline Underweight (IMT <18,50) & 4 & 1 & $25,0 \%$ \\
\hline Normal (IMT 18,50 - 24,99) & 53 & 18 & $34,0 \%$ \\
\hline Overweight (IMT $\geq 25,00)$ & 31 & 14 & $45,2 \%$ \\
\hline Obese (IMT $\geq 30,00)$ & 12 & 7 & $58,3 \%$ \\
\hline
\end{tabular}

Berdasarkan Tabel 5 maka diketahui bahwa proporsi penderita HV pada kelompok underweight $($ IMT $<18,50)$ sebanyak 25,0\% dimana dalam 4 sampel terdapat 1 orang dengan HV. Proporsi penderita HV pada kelompok normal (IMT 18,50 - 24,99) sebanyak 34,0\% dimana terdapat 18 orang dengan HV dalam 53 sampel. Proporsi penderita HV pada kelompok overweight (IMT $\geq 25,00$ ) adalah $45,2 \%$ dimana dari 31 sampel, 14 diantaranya merupakan penderita HV. Proporsi penderita HV pada kelompok obese (IMT $\geq 30,00$ ) sebanyak 58,3\% dimana dalam 12 sampel terdapat 7 orang dengan HV.

\section{DISKUSI}

Berdasarkan hasil penelitian ini didapatkan bahwa penderita HV pada guru dan pegawai Sekolah Menengah Kejuruan Pariwisata Dalung sebanyak 40\%.Pada 100 sampel penelitian 40 diantaranya menderita HV. Pada penelitian sebelumnya yang dilakukan pada mahasiswa kedokteran Universitas Jos di Nigeria tahun 2016 didapat prevalensi HV sebesar $16 \% \%^{5}$, sehingga prevalensi yang didapat pada penelitian ini lebih tinggi dibandingkan penelitian lain. Prevalensi yang lebih tinggi dapat disebabkan karena faktor internal dan eksternal seperti penggunaan sepatu yang kurang tepat 
(sepatu yang panjangnya tidak sesuai dengan ukuran kaki dan penggunaan sepatu high heel) yang dapat menimbulkan HV. ${ }^{14,15}$ Penelitian lain menyebutkan bahwa kejadian HV pada orang yang menggunakan sepatu lebih banyak daripada orang yang tidak menggunakan sepatu. ${ }^{11}$ Alasan seseorang menggunakan sepatu salah satunya adalah karena tuntutan pekerjaan seperti seorang guru dan pegawai di sekolah. ${ }^{11}$

Pada penelitian ini didapatkan proporsi penderita HV pada kelompok jenis kelamin pria sebanyak $29,4 \%$ sedangkan proporsi penderita HV pada kelompok jenis kelamin wanita sebanyak $51,0 \%$. Hasil distribusi penderita HV berdasarkan jenis kelamin pada penelitian ini sesuai dengan beberapa hasil penelitian sebelumnya diantaranya adalah yang dilakukan di Nigeria dimana prevalensi HV lebih tinggi pada mahasiswa kedokteran dengan jenis kelamin wanita dibandingkan dengan pria. ${ }^{5}$ Sejalan dengan hasil penelitian tersebut, sebuah studi meta analisis juga menyebutkan bahwa prevalensi HV pada wanita lebih tinggi dibanding pada pria. ${ }^{10}$ Hasil ini juga didukung oleh penelitian yang dilakukan di Boston dimana prevalensi HV dua kali lebih tinggi pada wanita dibandingkan pada pria. ${ }^{7} \mathrm{Hal}$ ini dikarenakan penggunaan alas kaki seperti high heels pada wanita dapat menimbulkan HV akibat penempatan tekanan secara langsung pada sendi metatarsophalangeal pertama dan menyebabkan perubahan bentuk serta menimbulkan peradangan akibat sepatu high heels. ${ }^{15}$

Proporsi penderita HV berdasarkan usiaditemukan lebih besar pada rentang usia 26-35 tahun. Hasil distribusi penderita HV berdasarkan usia pada penelitian ini tidak mengalami peningkatan proporsi meskipun beberapa penelitian sebelumnya dikatakan bahwa HV lebih banyak ditemui pada usia yang lebih tua. Pada penelitian meta analisis yang dilakukan oleh $\mathrm{Nix}^{10}$ dikatakan bahwa prevalensi HV meningkat seiring dengan pertambahan usia. Hal ini juga didukung oleh penelitian yang dilakukan di antara mahasiswa kedokteran di Universitas Jos, Nigeria, didapatkan hasil bahwa prevalensi HV lebih tinggi pada kelompok usia yang lebih tua. ${ }^{5}$ Namun hal ini tidak sesuai dengan penelitian yang dilakukan di Korea dimana ditemukan bahwa HV tidak secara signifikan berhubungan dengan usia. Hal ini menunjukkan bahwa HV berkembang sebelum usia 40 tahun. ${ }^{16}$ Usia merupakan prediktor yang buruk untuk kondisi HV. ${ }^{17}$ Serupa dengan pernyataan diatas, terdapat pula penelitian yang menunjukkan bahwa tidak ada hubungan yang signifikan pada seluruh kelompok usia yang diteliti dengan kejadian HV. ${ }^{7}$

Proporsi penderita HVditemukanlebih besar pada kelompok obese (IMT $\geq 30,00$ ) sebanyak $58,3 \%$, diikuti kelompok overweight (IMT $\geq 25,00$ ) sebanyak 45,2\%, kelompok normal (IMT 18,50 - 24,99) sebanyak 34,0\%, dan kelompok underweight (IMT <18,50) sebanyak 25,0\%. Hasil distribusi penderita HV berdasarkan IMT pada penelitian ini sesuai dengan beberapa penelitian sebelumnya diantaranya adalah penelitian yang dilakukan di Korea dikatakan bahwa IMT yang tinggi memiliki hubungan yang signifikan dengan kejadian HV. ${ }^{16} \mathrm{Hal}$ ini didukung oleh penelitian lainnya yang dilakukan oleh Wulan dan Rahayu ${ }^{15}$ disebutkan bahwa faktor eksternal yang berhubungan dengan HV salah satunya adalah IMT, IMT dengan kategori berat badan berlebih dapat menghilangkan fungsi lengkungan pada kaki akibat dari perubahan atau peningkatan tekanan pada telapak kaki sehingga terjadi HV. IMT yang berlebih disertai dengan faktor eksternal lain seperti penggunaan sepatu high heels akan menyebabkan penekanan pada otot abduktor sehingga terjadi posisi valgus. ${ }^{15}$ Otot abductor hallucis yang biasanya terletak pada bagian medial metatarsophalangeal pertama secara bertahap bergeser ke sisi plantar sendi. Otot adductor halluces dan flexor hallucis brevis secara progresif meningkatkan postur deviasi lateral phalang proksimal. Stretch yang berlebihan pada medial collateral ligament menghilangkan sumber kekuatan yang penting pada sisi medial sehingga menyebabkan $\mathrm{HV} .{ }^{4}$ Selain itu penggunaan sepatu high heels menyebabkan kaki lebih dorsifleksi sehingga tekanan yang kuat dibebankan pada kaki bagian anterior dan menyebabkan kaki menjadi rentan untuk terkena HV. ${ }^{15}$

Bagi peneliti yang ingin mengembangkan penelitian ini agar selanjutnya menggunakan populasi yang memiliki faktor risiko lebih tinggi untuk terkena hallux valgus, jumlah sampel yang lebih besar dengan metode random sampling dan dengan cakupan wilayah yang lebih luas. Bagi responden agar memberikan perhatian yang lebih pada kesehatan kaki dengan memerhatikan faktor-faktor risiko dari hallux valgus. Selain itu, Alat ukur untuk diagnosis penderita hallux valgus pada penelitian ini hanya berdasarkan pengukuran menggunakan goniometer sehingga untuk diagnosis lebih lanjut diperlukan pemeriksaan penunjang seperti radiografi.

\section{SIMPULAN}

Simpulan dari hasil penelitian ini adalah prevalensi penderita hallux valgus pada guru dan pegawai Sekolah Menengah Kejuruan Pariwisata Dalung di Badung adalah 40\%. Proporsi penderita HV berdasarkan jenis kelamin lebih besar pada wanita daripada pria, berdasarkan usia lebih besar pada kelompok usia 26-35 tahun, berdasarkan indeks massa tubuh (IMT) yang terbanyak adalah pada kategori obese.

\section{DAFTAR PUSTAKA}

1. Lazzarini PA, Hurn SE, Fernando, Malindu E, JenSD, Kuys SS, Kamp MC, Reed LF. Prevalence of foot disease and risk factors in general inpatient populations: A systematic review and meta-analysis. BMJ Open.2015. 5(11). pp. 115.

2. Deschamps K,Birch ID, Kaat M, Giovanni A. Gait \& Posture The impact of hallux valgus on foot kinematics : A crosssectional, comparative study, Gait \& Posture. Elsevier B.V. 2010. 32(1). pp. 102-106.

3. Ayub A, Yale S, dan Bibbo D. Common Foot Disorders. Clinical Medicine \& Research. 2005. 3(2). pp. 116-119.

4. Neumann DA. kinesiology to life and provide the. Second edition. Mosby Elseiver.2010.

5. Ekwere E, Usman Y, dan Danladi A. Prevalence of hallux valgus among medical students of the University of Jos. Annals of Bioanthropology. 2016. 4(1). p. 30.

6. Perera AM, Mason L, Stephens MM. The Pathogenesis of Hallux Valgus, The Journal Of Bone And Joint Surgery. 2011. 93(17). pp. 1650-1661. 
7. Nguyen USDT, Hillstrom HJ, Li W, Dufour AB, Kiel DP, Procter-Gray E, Gagnon MM, Hannan MT. 'Factors associated with hallux valgus in a population-based study of older women and men: the Mobilize Boston Study'. Osteoarthritis and Cartilage. Elsevier Ltd. 2010.18(1). pp. 41-46.

8. Menz HB, Fotoohabadi, Mohammad R, Wee E, Spink MJ. Validity of self-assessment of hallux valgus using the Manchester scale. BMC Musculoskeletal Disorders. 2010. 11(215). pp. 1-6.

9. Hendry GJ, Fenocchi L, Woodburn J, Steultjens M. Foot pain and foot health in an educated population of adults: Results from the Glasgow Caledonian University Alumni Foot Health Survey. Journal of Foot and Ankle Research. 2018. 11(1). pp. 1-15.

10. Nix S, Smith M, dan Vicenzino B. Prevalence of hallux valgus in the general population: A systematic review and meta-analysis. Journal of Foot and Ankle Research. 2010. 3(1). pp. 1-9.

11. Shine. Incidence of Hallux Valgus in a Partially Shoe-wearing Community.British Medical Journal. 1965. 1. pp. 1648-1650.

12. Janssen DMC, Sanders AP, Guldemond NA, Hermus J, Walenkamp G, Lodewijk W.A comparison of hallux valgus angles assessed with computerised plantar pressure measurements, clinical examination and radiography in patients with diabetes. Journal of Foot and Ankle Research. 2014. 7(1). pp. 1-9.

13. Choa R, Sharp R. dan Mahtani KR. Hallux valgus. British Medical Journal. 2010. 341. pp. 778-779.

14. Klein C, Groll-Knapp E, dan Kundi M. Increased hallux angle in children and its association with insufficient length of footwear: A community based cross-sectional study'. BMC Musculoskeletal Disorders.2009. 10(1). pp. 1-7.

15. Wulan AJ. dan Rahayu A. Risiko Pemakaian Sepatu Hak Tinggi bagi Kesehatan Tungkai Bawah. Majority. 2016. 5(3). pp. 22-27.

16. Cho NH, Kim S, Kwon DJ, Kim HA. 'The prevalence of hallux valgus and its association with foot pain and function in a rural Korean community'. 2009.pp. 494-498.

17. Turan I. Correlation between hallux valgus angle and age. J Foot Surg. 1990; 29:327-9. 88. 